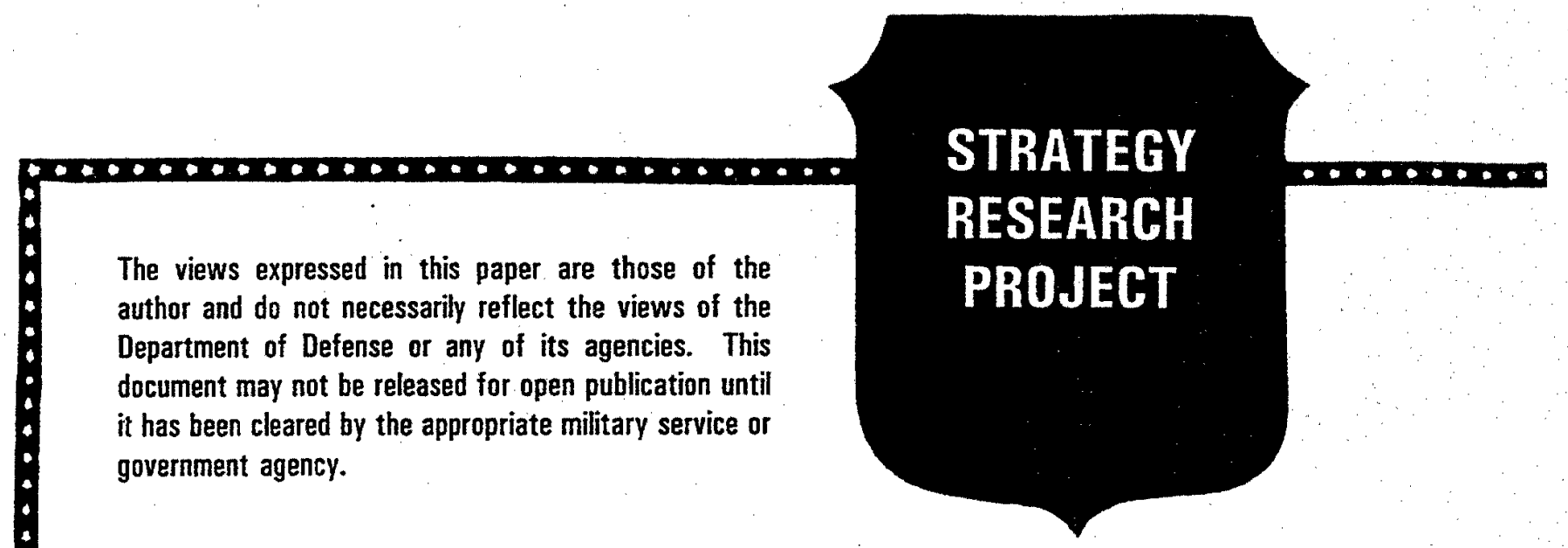

\title{
ARMY STAFF TRANSFORMATION INITIATIVES
}

\author{
BY \\ LIEUTENANT COLONEL BEVERLY M. STIPE \\ United States Army \\ DISTRIBUTION STATEMENT A: \\ Approved for Public Release. \\ Distribution is Unlimited.
}

USAWC CLASS OF 2002

U.S. ARMY WAR COLLEGE, CARLISLE BARRACKS, PA 17013.5050 20020502071 
USAWC STRATEGY RESEARCH PROJECT

\author{
Army Staff Transformation Initiatives
}

by

LTC Beverly M. Stipe

U.S. Army

COL Rick Jones

Project Advisor

The views expressed in this academic research paper are those of the author and do not necessarily reflect the official policy or position of the U.S. Government, the Department of Defense, or any of its agencies.

U.S. Army War College

CARLISLE BARRACKS, PENNSYLVANIA 17013

DISTRIBUTION STATEMENT A:

Approved for public release.

Distribution is unlimited. 


\section{ABSTRACT}

AUTHOR: $\quad$ LTC Beverly M. Stipe

TITLE: $\quad$ Army Staff Transformation Initiatives

FORMAT: Strategy Research Project

DATE: 09 April 2002 PAGES: 27 CLASSIFICATION: Unclassified

Force Management is the process whereby mission-ready Army organizations are established and fielded. Forces and equipment are validated, prioritized, developed, integrated, synchronized, fielded, and/or modernized within this framework. As a key transformation initiative, and under the direction of the Secretary of the Army, General Shinseki created the Office of the Deputy Chief of Staff for Programs (ODCSPRO) on 1 December 2000 as the responsible agent for Army force management initiatives. The ODCSPRO is on point for the Army to develop the weapon systems necessary to meet the CSA's guidance of transforming to a lighter, more lethal, and agile force. Of great concern is ensuring that the ODCSPRO is adequately structured and manned to fulfill force management and budget functions in light of the significant responsibility of weapon system acquisition and transformation from the legacy to objective force. The argument centers on the functional capabilities of each directorate within the ODCSPRO, and their ability to conduct force management as new programs are created under the auspices of Army Transformation. 


\section{TABLE OF CONTENTS}

ABSTRACT ......................................................................................................................................................... III

BACKGROUND ........................................................................................................................................................... 2

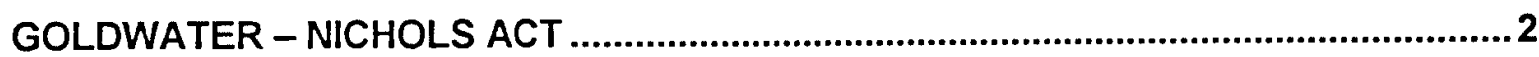

CHAPTER V - A PIVOTAL CHAPTER FOR THE ARMY STAFF ....................................

PROJECT QUICKSILVER TRANSFORMATION INITIATIVES ..........................................4

PROJECT VANGUARD TRANSFORMATION INITIATIVES..........................................5

THE EVOLUTION OF THE ODCSPRO …...............................................................................................................5

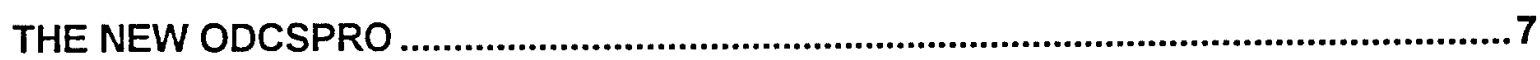

KEY WORKING RELATIONSHIPS ...............................................................................

STRATEGIC PLANNING ....................................................................................................................................9

ODCSPRO STRATEGIES ............................................................................................. 10

ORGANIZATIONAL PLANNING.................................................................................................................11

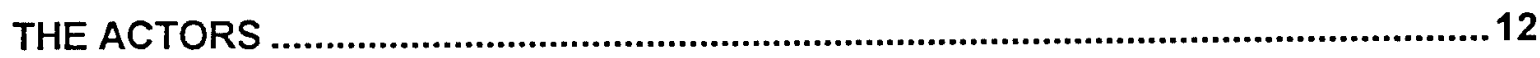

RECOMMENDATIONS..................................................................................................................................15

SUMMARY ............................................................................................................................................17

ENDNOTES ...................................................................................................................................................19

BIBLIOGRAPHY........................................................................................................................................................... 


\section{ARMY STAFF TRANSFORMATION INITIATIVES}

"MOST MILITARIES DO CHANGE, BUT IN MOST CASES, IT IS WHEN WARTIME PRESSURES, WARTIME SETBACKS FORCE THEM INTO IT.... TODAY, WE SEEK TO CHANGE IN A TIME OF RELATIVE PEACE, IN A TIME WHEN OUR COUNTRY ENJOYS ECONOMIC PROSPERITY, AND A TIME WHEN WE HAVE BOTH A STRATEGIC PERSPECTIVE AS A LEADING NATION OF THE WORLD, AND ALSO AT A TIME WHEN WE

HAVE THE TECHNOLOGICAL POTENTIAL TO DO SOMETHING ABOUT IT.... WE DO HAVE A WINDOW OF OPPORTUNITY, AND THE ARMY IS EMBARKING ON ITS MOST SIGNIFICANT CHANGE IN ABOUT A CENTURY."

\section{-General Eric K. Shinseki, Chief Of Staff, Army}

The Army transformation program that General Shinseki, the current Chief of Staff of the Army (CSA), announced during the 1999 Association of the United States Army Conference in Washington, D.C., is the single most visionary initiative the Army has been subjected to in decades. True, his vision incorporates plans for a lighter, more lethal and deployable fighting force with technologically advanced weapon systems, but on the surface, this is only the beginning. He is also spearheading a revolution in organizational management that is without peer in the military component. Often overlooked in the haste of transformation, General Shinseki is promoting an administrative and cultural change on the Army Staff that captures the essence of efficiency and excellence, while also aligning major subordinate staff elements with those of the Joint Staff and the Office of the Secretary of Defense (OSD).

The role of the Army is to conduct land-based combat operations. Within this construct, the Army's major responsibilities are to equip, train, sustain, and resource the forces that conduct combat operations. ${ }^{1}$ The National Command Authority (NCA) assigns the Army's strategic missions, and the warfighting Commanders in Chief (CINCs) assign the operational and tactical missions, and determine the requirements necessary to achieve these missions. The Office of the Secretary of Defense (OSD) validates the strategic, operational, and tactical requirements, and the Army force management process develops the Army programs necessary to meet the warfighter's needs. OSD also resources the Army so it will be better prepared to meet the challenges of the $21^{\text {st }}$ century. The issue within the framework of Army Staff transformation is to determine the most suitable and economic means to accomplish the force management process. This paper discusses Army Staff transformation initiatives that have been implemented, and recommends proposals to further streamline the force management process while better serving the Army warfighters. The purpose of this paper is not to provide an extensive understanding of the complexities of force management, but rather to identify areas within the force management framework where efficiencies can be gained, 
where Army Staff transformation agendas can be capitalized upon, and where certain functions within the force management framework can best be managed.

\section{BACKGROUND}

From January to June 1982, the Department of the Army Inspector General (DAIG) conducted a force modernization inspection that focused on the Army's ability to equip the force, manage force modemization, and conduct new system fielding. This inspection, the Army's first major initiative toward total transformation, initiated the transition of the Army of the 1980 s to the Army of 2000. Within the 856 findings sub-grouped into 49 categories, the Office of the Inspector General (IG) determined that the Army must conduct a major overhaul of the force management process, including development, acquisition, staffing, sustainment and modernization. The Army Life Cycle Management Model ${ }^{2}$ provided the structure for a coherent understanding of the major problem areas, which included improving the force management function of total force integration, or "the synchronized, resource-constrained execution of an approved force development program to achieve systematic management of change." 3

Materiel developers (acquisition managers, program managers, and product managers) are the nucleus of the procurement process. They document requirements and conduct cost estimates prior to initiating the research, development, and acquisition cycle for a new system. During the late 1970's and early 1980's, public pressure called for defense spending controls to eliminate duplicative efforts, improve budget management, and eliminate fraud, waste, and abuse of taxpayer dollars, an amount that totaled roughly $\$ 23$ billion per year. This waste and mismanagement consumed "about one third of the total weapon procurement expenditures at that time." ${ }^{4}$ Recognizing significant shortfalls in defense acquisition management procedures and functions, President Reagan appointed a Blue Ribbon Commission in 1986, more informally referred to as the Packard Commission, to recommend processes that would streamline procurement practices, and force materiel developers to plan for long-term modernization requirements rather than to react to short-term threat-based crises. The most significant results of the Packard Commission were the placement of civilian policy-makers in responsible control of defense acquisition management, the establishment of the position of the Vice Chairman of the Joint Staff to oversee defense acquisition management, and the provision for defense acquisition executives (Program Executive Officers - PEOs) with direct oversight of weapon system Program Managers (PMs). 


\section{"WE'VE PUT THE SECRETARIAT ON A DIET AND REFOCUSED THEM ON PRECISELY}

WHAT THE SECRETARY OUGHT TO BE DOING."

-Thomas White, Secretary of the Army

\section{GOLDWATER - NICHOLS ACT}

The 1986 Goldwater-Nichols Act ${ }^{5}$ resulted in changes, not only to the joint military departments, but also to the separate services. In fact, Congress was principally interested in a substantial reorganization that focused on the military's ability to modernize the force. ${ }^{6}$ One of the main goals of the Goldwater-Nichols Act was to relate and tie funding levels to strategic planning. This required the services to restructure their acquisition processes to demonstrate economic credibility and responsibility to Congress based on their ability to balance fiscal imperatives against fiscal constraints. One of the most direct results of the Goldwater-Nichols Act was the establishment of the Army Acquisition Corps (AAC). Within the AAC, the Defense Acquisition Staff Coordinators (DASC) are specially trained in contracting, procurement, and program management, and are responsible for maintaining fiscal restraint in program and defense acquisition management. They also serve as the interface between the Army Staff and the Office of the Chief of Legislative Liaison (OCLL), the staff element responsible to provide credibility for and promote Army programs to Congress.

\section{Chapter V - a pivotal chapter for the Army Staff}

Chapter $V$ of the Goldwater-Nichols Act addressed the most significant Army Staff transformation requirements. ${ }^{7}$ This directive required the service secretaries and service chiefs to enhance civilian control of the Department of Defense, and eliminate the duplication of effort between the secretariats and service staffs. In specifically addressing each service individually, Chapter $V$ limited the Army Secretariat to one Under Secretary position and five Assistant Secretaries, two of which were specifically mandated: Assistant Secretary of the Army (Manpower and Reserve Affairs) and Assistant Secretary of the Army (Civil Works). ${ }^{8}$ Chapter V similarly limited the Army Staff to one Vice Chief of Staff and five Deputy positions, with the provision for three additional Assistant Chiefs of Staff. For years, the Army has operated with only four Deputy Chiefs of Staff (Personnel, Intelligence, Operations, and Logistics). The establishment of the Office of the Deputy Chief of Staff for Programs (ODCSPRO) as the fifth Army Deputy Chief of Staff position conforms to the restrictions of the Goldwater-Nichols Act, and more importantly, fills a void that has long gone unrecognized by the Army force management proponents. 
In keeping with the theme for civilian control of the military, Chapter $V$ also directed a reorganization of military department functions and responsibilities. Generally, roles and missions that could be considered purely managerial, or business-related, were consolidated within the Army Secretariat, and those directly associated with military operations, including Joint Chief of Staff (JCS) interface, were maintained within the Army Staff. Commensurate with this reorganization effort, the DCSOPS was given additional mandates for reorganization based on the findings of a 1986 DAIG follow-up inspection to the Goldwater-Nichols Act implementation. The DAIG recommended that ODCSOPS be structured for and given the responsibility for force integration (the management of units, priorities, resources, modernization, and transformation initiatives) in view of the fact that no Army Staff element was in decisive control of program and acquisition management functions. Additionally, the DAIG recommended that ODCSOPS move several Program and Budget Office staff positions to the Assistant Secretary of the Army (Financial Management and Comptroller) (ASA(FM\&C)) and the Army Budget Office (ABO). This realignment effort was designed to centralize personnel resources where they could more readily manage total expenditure control, and provide oversight of all major Army systems to the annual budget process. As this change was implemented, ODCSOPS combined the remainder of their budget personnel with a slice of force integrators, and formed the Resource Analysis and Integration Office. This grouping created a single ODCSOPS section responsible for planning, programming, budgeting, and execution - a structure that solidified the Army requirement for the force integration functions of program validation and prioritization to rest solely within ODCSOPS. The former ODCSOPS Force Integration Office became the ADCSOPS (Force Development and Integration), and gained the majority of the force structure increases for ODCSOPS. An acknowledged mission of the Force Development and Integration Office was to determine priorities and requirements for combat weapon systems, and command, control, and communications, systems ${ }^{9}$, a potentially contentious issue for ODCSOPS and ODCSPRO as transformation roles, missions, functions,

and initiatives were established and prioritized for each staff element. Of particular concern was the development of new mission statements for these sections based on the Army Staff transformation initiatives of the late 1990's.

\section{Project Quicksilver Transformation Initiatives}

In the late 1980's and early 1990's, several projects documented and recommended solutions for the imbalances in the Table of Distribution and Allowance (TDA) and force levels (reduction requirements) brought on by the implementation of the Goldwater-Nichols Act. In 
1989, Project Quicksilver, a CSA-directed panel, was chartered to develop and recommend solutions without sacrificing the readiness of the force to offset the pending budget restrictions and the large personnel reductions mandated by the Goldwater-Nichols Act. ${ }^{10}$ Project Quicksilver assessments from 1989 through 1997 recommended the reduction of the Army Table of Organization and Equipment (TOE) endstrength by 160,000 personnel through the elimination of four divisions from the active force. The single most significant drawback to Project Quicksilver was that, while the panel recommended the numbers to be reduced, they failed to articulate a reduction strategy, and provided no indication of which organizations should be reduced or how the reductions would affect the Army. The panel also failed to interpret how this transformation would affect the major elements of the Army Staff, and to what degree this initiative would affect the Army's ability to coordinate acquisition management and joint readiness issues. Nonetheless, Army leaders did reduce the force structure by 160,000 positions through another CSA-directed panel called Vanguard.

\section{Project Vanguard Transformation Initiatives}

In 1990, the CSA transformation task force, Project Vanguard, was chartered to develop a plan to implement Quicksilver restructuring initiatives. ${ }^{11}$ Project Vanguard provided a comprehensive scrub of the TDA, and recommended changes to complete Army force structure realignment initiatives in accordance with the Goldwater-Nichols Act, including the identification of the four divisions to be deactivated. It also laid the foundation for the Quicksilver reduction strategy, and proposed several changes to Major Army Command Staffs, installation staffs, and the Army Staff, including a realignment of the Army Staff that mirrored Army Secretariat and Joint Staff roles and functions. Project Vanguard proposed further studies of force structure and realignment management, to include the Army Reserve Command initiative, Battle Laboratory studies, and the Louisiana Maneuvers. ${ }^{12}$ Using this as a backdrop for Army Staff and Secretariat transformation initiatives, the remainder of this paper will provide an understanding of the Army Staff realignment, the development of the ODCSPRO, and the force management process as it relates to ODCSOPS, ODCSPRO, and the CSA Transformation Campaign Plan.

\section{THE EVOLUTION OF THE ODCSPRO}

"As part of his effort to streamline the headquarters operation, [Secretary] White is giving most of the principal Army staff officers, such as the deputy chiefs of staff for personnel and logistics, an advise and assist relationship with the Assistant Secretary of the Army most closely tied to their responsibilities. The titles of the principal Army staff officers will revert to the 
traditional Army 'G' format. In other words, the Deputy Chief of Staff for Personnel will become the G-1, the Deputy Chief of Staff for Intelligence will become the G-2, and so on."13 Additionally, White stated that the DCSPRO will become the G-8, and will focus on the Army's future forces and force structure.

Until December 2000, ODCSOPS was solely responsible to the CSA for force management and force integration. Force management is the process of determining force requirements and alternative means of resourcing requirements by allocating resources and assessing the utilization of resources to accomplish Army functions and missions. It includes all aspects of doctrine, training, organization, materiel, and combat developments. It includes force integration, validation, and prioritization of Army combat requirements. ${ }^{14}$ CINCs determine their warfighting requirements based on current and future threat assessments. They articulate these requirements in their integrated priority lists (IPL), and forward them to the Chairman of the Joint Chiefs of Staff. The JCS then assesses the requirements, and forwards them to the service components for integration into their respective force management processes. Provided the requirements are thoroughly documented, ODCSOPS validates the CINC IPL requirements, and integrates them into a plan for future development, modernization, or modification based on the weapon systems available in the Army inventory, and on those modernization or modification initiatives currently in the research, development, or acquisition phases of the Army Life Cycle Model. ODCSOPS then prioritizes these requirements and synchronizes them into the Army Program after they have been validated and accepted by the Army Requirements Panel and the Army Requirements Oversight Council (AROC). ${ }^{15}$ The AROC forwards the validated programs to the Joint Requirements Panel (JRP) - an O6-level advisory panel to the Joint Requirements Board (JRB), which reviews the requirements for joint applicability and fundability. Once validated here, the JRB - an O7-level board, coordinates service input into the Joint Requirements Oversight Council (JROC), where the programs are either returned to the Army for further study, or are approved and integrated into the JROC process.

To provide systemic control over weapon system programs without relinquishing the processes of requirement validation and prioritization, ODCSOPS divested itself of the responsibility for program management and acquisition. This transformation initiative resulted in the formation of a new Army Staff element, the Office of the Deputy Chief of Staff for Programs (ODCSPRO), which was created on 1 December 2000 . Headed by a Lieutenant General, this new organization absorbed all of the major ODCSOPS functions of the Assistant Deputy Chief of Staff for Operations and Plans (ADCSOPS) (force integration, program budgeting, and major Army studies). The Force Development (FD) Directorate, the Quadrennial Defense Review 
Office (QDRO), the Program, Analysis and Evaluation Directorate (PAED), and, a year later, the Center for Army Analysis (CAA) were all transferred to the ODCSPRO. ODCSPRO's focus is the AROCIJROC process described above as it emphasizes the importance of fielding materiel solutions to combat future adversarial threats.

\section{The New ODCSPRO}

Given doctrine, training, leader development, organizational, materiel, and soldier systems (DTLOMS) conditions and constraints as programs are developed, the ODCSPRO is responsible for the future of the Army through programming, program analysis and evaluation, materiel integration, and centralized management of HQDA studies and analyses, as well as extemally directed reviews. ODCSPRO synchronizes the Army Program (formerly the Army Plan) in support of the Army vision through independent assessments and weapon system integration. The DCSPRO is the principal military advisor to the $A S A(F M \& C)$ on matters relating to The Army Program, and serves as the principal advisor to the Army Chief of Staff on singleand multi-service (joint) materiel requirements, systems and DTLOMS integration, and execution over the life cycle of the materiel and programs. He provides centralized management of the HQDA Studies and Analysis Program (SAP), and is the internal provider of analysis support to HQDA using CAA, Federally Funded Research and Development Centers (FFRDC) such as the RAND Corporation and MITRE Corporation, as well as other contracted resources. He advocates the Army vision with the Office of the Secretary of Defense (OSD), the Joint Staff, the CINCs, the services (Army, Navy, Air Force, and Marines), and external agencies.

\section{Key Working Relationships}

The DCSPRO serves as the military deputy to the ASA(FM\&C). In this capacity, he performs advisory functions on all Army programs, and assists the ASA(FM\&C) in advocating the Army budget to the Joint Staff, OSD, and Congress. As the G-8, the ODCSPRO key external working relationships include OSD, the J-8 on the Joint Staff, the Secretary of the Army (SecArmy), and the Army Secretariat. Key internal relationships include the Army Staff, OCLL, Major Commands (MACOMs), the CINCs, and the other services. The ODCSPRO also serves as the fiscal proponent for resources, as well as the single point of entry to the Army Staff for tests and simulations of new products. The ODCSPRO is comprised of four separate directorates (FD, PAED, QDRO, and CAA) with over 600 employees, making it the second largest Deputy Chief of Staff element behind ODCSOPS. 
The FD Directorate under ODCSPRO is segregated into ten separate divisions within the Directorate of Materiel (DOM) and the Directorate of Integration (DOI). FD promotes Army programs within OSD, the Joint Staff, regional CINCs, the services, and external organizations that influence defense decision-making, is responsible for translating approved DTLOMS requirements into programs, and provides life cycle management of those weapons systems. FD executes fielding synchronization, develops Army modernization, recapitalization, and investment strategies for the Army's lethal weapon systems, and executes unit set fielding and total package fielding plans. FD also coordinates all joint requirements within the AROC, the $J R P$, the JRB, and the JROC, performs warfighting analyses, and leverages technology to optimize the impact of new weapon systems on the total force. FD is the largest ODCSPRO directorate, and is headed by a Major General. DOM is comprised of the following weapon system (hardware) divisions: Full Dimension Protection (FDP), dominant Maneuver (FDM), Precision Strike (FDS), Focused Logistics (FDL), and Information Superiority (FDI). The Colonels who head these divisions oversee the workforce that is responsible for taking each weapon system from inception to retirement. $\mathrm{DO}$ is comprised of the following integration divisions: Acquisition Resources (FDA), Horizontal Fielding (FDH), Technical Integration (FDT), Programs and Priorities (FDR), and Integration Analysis (FDQ). These divisions are responsible for conducting fielding schedule coordination, Joint and Army studies, software integration, and resourcing. The workforce in these divisions consists of Force Integration Staff Officers (FISOs) - military system representatives, analysts, administrative and contractor support. The system FISOs serve as the central coordinators for all actions associated with each specific weapon system. Equally important to the FD mission are the liaison staff officers from the Directorate of Information Systems for Command, Control, Communications, and Computers (DISC4), and from the Assistant Secretary of the Army for Acquisition, Logistics, and Technology (ASA(ALT)), who complete the team of officers working to meet the requirements of the CSAs transformation agenda.

PAED is responsible for The Army Program Objective Memorandum (POM), the Future Year Defense Plan (FYDP), and overall management of the programming phase of the Planning, Programming, Budgeting, and Execution System (PPBES). PAED serves as the executive agent for The Army Program to OSD, provides independent analysis of programs and alternatives, and recommends budget and weapon system priorities to the DCSPRO. PAED is also responsible for managing the Program Budget Database (PBD), and submitting the approved Army Program to the Army Budget Office, which serves as the framework for the 
Army Budget Estimate Submission (BES). This staff also provides independent analytic support throughout the HQDA staff as an extension to their primary budget responsibilities.

The Center for Army Analysis, formerly under the Director of the Army Staff (DAS), is a Field Operating Agency (FOA) that began reporting to the DCSPRO on 7 January 2002. It is, in effect, the clearinghouse for all Army studies, analysis, and simulations. There currently is no established working relationship between CAA and the DCSPRO. CAA's mission is to analyze strategic concepts and military planning options, estimate requirements to support the Army's input into the Planning, Programming, Budgeting and Execution System (PPBES) cycle, evaluate Army forces and force structure capabilities, design Army forces, and evaluate force alternatives. CAA also develops theater level force-on-force scenarios, and conducts resource analyses based on scenario findings. The focus of CAA is to determine solutions for future combat environments, to "assess strategy, strategic concepts, broad military options, resource allocation alternatives, and analysis of Army force level capabilities in the context of joint and combined forces." 16 CAA assists in validating CINC requirements and modeling the Total Army Analysis (TAA) using computer simulations. As a tool for developing future systems, CAA is well placed in ODCSPRO, but this could potentially serve as the breeding ground for DCSPRO bias in promoting programs and studies for systems that do not necessarily meet CINC requirements. Agendas for special or preferred solutions may take priority over other more capable systems. Regardless, CAA is chartered to eliminate duplication of effort in studies and analyses, and provide recommendations for programs that will achieve maximum value, both monetarily and systemically.

Under the management of the ODCSPRO for the 2001 Quadrennial Defense Review, the QDR Office conducts studies and assessments to posture the Army to stay ahead of uncertain future events that would provoke military intervention. Ideally suited in the ODCSPRO, the QDR Office studies mid-term and long-term contingencies, provides recommendations on force structure, organization, and infrastructure with a focus on joint and combined operations, designs program options to prioritize modernization efforts, and devises plans and programs that take full advantage of the transition of information operations, intelligence, and space enablers. The QDR Office identifies key issues in time to develop, coordinate, and influence positions and study group recommendations, communicates Army positions and perspectives, completes analyses, conclusions, and recommendations that reflect Army requirements, capabilities, and equities, and coordinates all input with the Office of the Under Secretary of Defense for Acquisition, Technology, and Logistics (OUSD(ATL)). The QDR 
Office provides the ODCSPRO with the ability to wargame alternatives to warfighter scenarios that stem from the National Security Strategy (NSS).

\section{STRATEGIC PLANNING}

The Secretary of Defense (SECDEF) has mandated alignment of the service staffs with their respective secretariats in order to eliminate duplicative efforts, reduce personnel requirements, and ensure effective and efficient operations. Army modernization provides an excellent instrument to translate critical transformation objectives into warfighting capabilities by taking validated and prioritized programs and incorporating them into the force management process for development. The force management process is subdivided into the four separate, but distinct categories of organizational integration, force integration, document integration, and system integration. As the ODCSPRO matures, it will implement several strategies to accomplish its force management and budgetary missions. In a sense, ODCSPRO will learn from standing organizations while putting into practice guidance from the CSA and Army Secretariat in terms of organizational realignment and force reduction compliance. Doing so will allow the ODCSPRO to establish credibility, efficiency, and effective management techniques that will allow action officers to field the best solutions to military priorities. Three distinct strategies will provide ODCSPRO with a solid foundation for future operations. The most significant changes can and will occur in FD, and, as such, will be the focus of discussion for the remainder of this study.

\section{ODCSPRO Strategies}

The first ODCSPRO strategy, as stated by the former DCSPRO, LTG Kevin Byrnes, is to streamline operations by eliminating redundancy and realigning the workforce to meet mission needs. Information technology and administrative functions, those performed individually by each separate directorate and division, will be reorganized into a central output and support facility. This "customer support office" will manage information technology (IT) and software support, as well as distribution, administrative staffing, and staff action processing. Condensing these roles will provide ODCSPRO action officers with the IT and administrative support that normally hinders or encumbers their workload. ${ }^{17}$ Several layers of bureaucracy can be eliminated. Because ODCSPRO organizations are not centrally located, require differing levels of support, and tend to routinely duplicate workloads, the only way to gain efficiencies and focus on major Army programs is to consolidate administrative, budgetary, and information technology (IT) functions into one location. This may also result positively in a reduction of manpower. 
Second, gaining efficiencies includes resource reduction, and the ODCSPRO has determined that, due to perceptions of impropriety, FD must reduce its reliance on contractors, who make up over 50 percent of the employee force. Historically, whether legal or not, Contract Man-year Equivalent (CMEs) employees have been allowed to perform in inherently governmental positions as FISOs. While they do not speak for the Army, and are not involved in decision-making forums, their presence, nonetheless, provides inconsistent perceptions of systemic reliance and, perhaps, bias or favoritism of one contractor over another in program or weapon system promotion. By removing CME employees as FISOs, System Integrators (SIs), Resource Managers (RMs), and Organizational Integrators (Ols), the ODCSPRO can achieve some limited resource efficiencies because contracted civilians cost more to hire and maintain than military officers or government civilians. It is important to note here for greater understanding that the personnel shortages experienced throughout the Army are not isolated. Per the current Army TDA, the Army Staff is undermanned by about 25 percent of its authorized military positions. FISOs, SIs, RMs, and Ols serve in multi-purpose roles, and the contracted civilians in these positions provide not only program oversight, but also program management continuity when vacancies occur. The DCSPRO anticipates an increase in active component officer strength to 100 percent based on the CSA's commitment to filling authorizations for force management positions. Converting CMEs to GS civilians to further civilianize ODCSPRO in accordance with SecArmy guidance may provide resource relief. ${ }^{18}$ Further, discussions with senior leaders indicate that reserve component (RC) officers can bridge the gap between authorized and assigned military personnel, and can serve to improve communication of requirements and processes between the active and reserve components. The ODCSPRO implementation plan reflects enhanced $R C$ integration. ${ }^{19}$ This proposal increases RC authorizations on the TDA from 14 to 38 , and converting up to 6 active component authorizations for division chiefs to $\mathrm{RC}$ authorizations, as these positions are currently being filled by RC Colonels.

The third ODCSPRO strategy is to separate the studies, budget, and joint programs (FDQ and FDR) from the DOI, and align them under a new SES position to improve management of these functions, provide greater continuity to the leadership of FD, and further integrate the ODCSPRO military and civilian workforces. These missions require 1-star oversight, and currently detract from the DOI mission, which is already complex and work intensive. Not only will adding a civilian SES position provide a growth structure for civilian leaders, but it will also add continuity to FD, an organization with a high tumover rate. 


\section{ORGANIZATIONAL PLANNING}

The ODCSPRO endeavors to protect Army interests in programs where there is significant joint applicability and where inter-service rivalry is the greatest or most anticipated. For example, space-based programs, national missile defense, and command, control, and communication architectures are emerging programs where the Army has great interest, and can pursue common (joint) agendas with weapon programs that are either currently in production, in product test and evaluation, or in research and development. Economies of scale in the methods of procurement will ensure the Army researches and develops weapon systems that are adaptable to other service systems when feasible. The vision of the ODCSPRO pledges to develop, independently assess, integrate, and synchronize Army hardware development programs in support of the Army vision, and this serves to propagate the CSA weapon system transformation initiatives.

\section{THE ACTORS}

ODCSPRO is the second largest of the Offices of the Deputy Chiefs of Staff. There are 601 assigned employees, 37 percent of which consists of military officers. Government civilian employees (GS) and contractors account for the remaining 63 percent of the ODCSPRO team. Managerial leaders (General officers and senior leaders) not counted in the total, are trained in strategic policy, acquisition procedures, and fiscal responsibility in much the same manner as the staff action officers and Division Chiefs. These senior officers provide strength to program management in their ability to identify shortfalls, visualize "next steps," create the foundation for new programs, and develop and synchronize Army requirements. They are also able to market their ideas based on current and future threats, and take the necessary steps to procure funding for major weapon systems. ODCSPRO has been directed by the CSA to reduce its overall endstrength by 75 positions, the bulk of which will be FD CME positions. Similarly, CAA should eliminate over 25 positions, the preponderance of which include administrative and technical support personnel. Reductions in any measure for PAED and QDRO would significantly disrupt operations due to the vastness and complexity of their assigned responsibilities. Current force manning levels are adequate to administer the responsibilities assigned to each organization.

Force integrators (FI) represent the interests of functionally dissimilar organizations from separate brigades to theater armies, and they assess the ability of functional systems to support major organizations. They also recommend the prioritization of resources, assess the impacts of organizational change on unit readiness, and link organizational requirements to resource allocation. ${ }^{20}$ Force Integration Staff Officers, or FISOs, are the "cradle to grave" supervisors of 
major weapon system programs. They are the interface between the Department of the Army and the user. FISOs focus on systems and fielding to deliver capabilities and functions to warfighting units. They shape the conditions for fielding the required capabilities in unit sets. They also coordinate and integrate DTLOMS and infrastructure requirements for the systems' life cycles, and are responsible for system fielding and sustainment. FISO responsibilities extend to representing user interests in materiel system management, reviewing and coordinating materiel requirements documents, recommending prioritization of materiel distribution and redistribution, participating in management decision reviews, and monitoring research, development, acquisition, tests, evaluation, and materiel change programs. In essence, the FISO's specific responsibilities include continuous coordination, integration, and synchronization of all aspects of new materiel systems into the Army force structure.

The FISO ensures that all actions necessary for Total Package Fielding are coordinated prior to unit fielding, and monitors the progress of all aspects of an assigned system throughout its developmental process to ensure that these requirements are staffed, approved, and satisfied. This includes new materiel, organizational change and documentation, logistical support, manpower spaces and required personnel (force structure), to include Military Occupational Specialty (MOS) training packages, infrastructure changes, and displacement or cascading of legacy equipment to the National Guard/Reserves. Because of the interrelationships of assigned responsibilities in materiel acquisition and combat development, close and continuous coordination between the Army Secretariat, HQDA Staff elements, other agencies, commands, and installations is required.

FISOs relate requirements and resources to the Army Transformation Campaign Plan, and maintain a critical link between ODCSOPS and the field units by providing quality products as required. Ideally, one FISO should be assigned to each major weapon system either currently in the Army inventory or in development. Given the conditions of the Transformation Campaign Plan, FISOs are the single most important representatives in the Army. They are managing or developing all legacy, interim, and objective force weapon systems, and provide the backbone to all materiel solution transformation initiatives. FISOs generally are senior Lieutenant Colonel former battalion commanders with little or no acquisition background. A month-long training course provides the backdrop in preparing them for their action officer duties, but in no way provides the critical awareness required for their comprehensive missions. Unfortunately, FISO responsibilities are not always limited to one major weapon system, and shortages have required some FISOs to manage two or more programs. This doubling of effort can fracture the focus on program priorities. To alleviate the stress created by the 
overextension of FISOs, CMEs have been hired to shoulder some of the program management burdens. This has also led to rampant hiring of CMEs.

FISOs have created, over time, an ad hoc team consisting of OIs, ASA(ALT) DASCs, and DISC4 liaisons. These "teams" working closely together provide the requisite composition for weapon system program management, and their coordination is absolutely essential as the CSA's transformation initiatives evolve. Poor coordination, lack of focus on the main efforts, and unavailability of some of the liaisons have frequently led to additional resource expenditure or program delays. These predicaments could jeopardize full focus and coordination on the CSA transformation initiatives.

Organizational integration is "the doctrine of change management that focuses actions on organizations to ensure the orderly introduction, incorporation, and sustainment of new structure and new materiel systems to develop a capable combat force within constrained resources." 21 The $\mathrm{OI}$ is responsible for the horizontal and vertical integration of DTLOMS across the force. While not the pivotal actor in the force management process, the OI represents the interests of functionally similar organizations, recommends resource prioritization, assesses the impact of organizational change on readiness, reviews organizational requirements and authorization documents, and provides guidance and oversight to the Army Secretariat Modified Table of Organization and Equipment (MTOE) Documentation Team. $^{22}$ Ols are the architects of force management and development in the Army Program. Their responsibilities extend to the Army National Guard and Reserves, multi-component units, and integrated divisions, with emphasis on MTOE/TOE adjustments, base realignment and closures, and TAA adjustments. Before the ODCSOPS and ODCSPRO separated, Ols were assigned to and managed their programs from within FD. Their assignment to the ODCSOPS has created a significant communication gap between the Ols and the FISOs, and has increased the risk of losing focus on the key elements of the transformation agenda. Answering to separate Deputy Chiefs of Staff, there is now more room for differing agendas to be worked on parallel axis, where once a united effort existed.

Liaisons to the ODCSPRO are provided by multiple sources. ASA(ALT) controls counterpart DASCs to the weapon system FISOs. Often, one DASC assists in managing more than one weapon system program. DASC responsibilities vary by program, but include coordinating milestone timelines with FISOs and system specific Program Managers. DASCs, while not co-located with the FISOs, are critical to interpreting requirements and holding contractors accountable for meeting precise development and delivery schedules. Their ability to represent weapon systems, develop testing and fielding schedules, and argue program 
positions to congressional staffers during House and Senate Armed Services Committee meetings is vital to the success or failure of program approval. The relationship between the FISO and DASC is crucial as programs move through requirements determination, research and development, milestone progression, and fielding phases, especially given the CSAS Transformation Campaign Plan initiatives. Maintaining this close relationship is imperative as it is easy to lose sight of seemingly insignificant events that, if exploited, could cost the government time and money. DASC representatives, at least one per weapon system division, must be assigned directly to the FD to ensure program stability.

DISC4 liaisons are the fourth, and final, critical members of the force management team. DISC4 representatives are currently assigned one per weapon system division, but work directly for the DISC4. These team members are branch specifically matched to the weapon system divisions (i.e. an Air Defense DISC4 representative manages FDS division air defense Command, Control, Communication, Computers, and Intelligence [C4I] programs), and coordinate all aspects of system communications and software specifications. More importantly, they work joint $\mathrm{C} 4 \mathrm{l}$ issues for the FISOs. For example, where technology can provide common user software or communications equipment across the services, the DISC4 representatives are able to easily recognize requirements and recommend solutions during the research and development phase of milestone progression. The most critical element of battlefield maneuver is not "steel on target," but rather, the ability to communicate across a broad spectrum of mediums. DISC4 representatives have the means necessary to accomplish multiple crosschecks as systems are developed. Their recommendations to the FISOs and DASCs play a major role during the development of interim and objective force systems for the CSAs Transformation Campaign Plan. Assigning these liaisons directly to the weapon system divisions will ensure that resources are not expended for systems that are not multi-service oriented.

\section{RECOMMENDATIONS}

The Army Staff has undergone considerable transformation. The initiative to establish the ODCSPRO has been the most significant Army Staff change management program in several decades. The ODCSPRO responsibilities are directly tied to the CSA's Transformation Campaign Plan because ODCSPRO manages the staff officers that will effect the changes to weapon systems and force structure. Within the ODCSPRO, the job of the FISO is overwhelming. If ODSCPRO is to meet the CSA's objectives with timely accuracy, FD must be filled to 100 percent of its personnel authorizations, be supplemented through TDA adjustments 
with critical liaisons (DASCs, OIs, and DISC4 representatives), and be fully integrated with reserve component officers who can communicate vital reserve and National Guard requirements. Acknowledging the requirement to reduce manpower and $C M E$ support, recommendations are listed herewith.

- CAA should remain under the ODCSPRO for a probationary period of three to five years. Because the purpose of moving CAA from the DAS to ODCSPRO was to establish a single HQDA data base for past, current, and proposed studies and analyses, and increase the value per dollar expended on studies (more focus/less waste), Army leaders must establish metrics to evaluate whether these actions actually transpire. If bias in studies and analyses occurs based on preferential behavior, CAA should immediately revert to the DAS to prevent program parochialism.

- Consolidate IT and administrative efforts in the ODCSPRO into one staff element to eliminate redundancy and establish resource efficiencies across the staff organization. A reduction of 13 to 15 administrative positions throughout ODCSPRO will result in cost and manpower savings, and will serve to standardize a quality support level across entire staff.

- Given the requirement to reduce ODCSPRO by 75 positions, a significant monetary savings can occur by eliminating 40 to $60 \mathrm{CME}$ staff positions because government civilians cost about two-thirds of contracted civilians. GS level employees whose positions currently remain unfilled on the TDA can replace these contractors. The objective is to balance authorizations with personnel assigned. GS employees offer similar or better stability and continuity, and this CME reduction will result in the removal of contractors from governmental relationships. It will also provide less bias in program support.

- By incorporating Reserve Component officers into FD/ODCSPRO, there will be noticeable improvement in AC/RC communication flow on requirements. Their assignment will provide RC expertise to the ARSTAFF on horizontal and vertical integration. The recommendation adds 18 to $20 \mathrm{LTC/COL} \mathrm{RC} \mathrm{officers} \mathrm{in} \mathrm{positions}$ currently held by CMEs.

- Create a FISO team. Clearly define mission of FISO (field complete unit sets IAW TCP, complete DTLOMS integration...) with an end state of a FISO team responsible for the continuous execution, coordination, distribution, and synchronization of materiel and unit systems from requirements determination through fielding to retirement. Move directly to 
FD the authorizations for one to three DASCs per weapon system division, and one DISC4 liaison per weapon system division from ASA(ALT) and DISC4. Move Ols back to FD as part of the FISO teams. ODCSPRO must be supplemented with representatives from $A S A(A L T)$ and DISC4 for program continuity and Congressional credibility.

\section{SUMMARY}

ODCSPRO is a complex and diverse organization with demanding responsibilities. The Army Staff has not seen such a significant change as the establishment of the ODCSPRO since the early 1970s when the Deputy Chiefs of Staff were established. The workforce is committed to implementing the CSAs Transformation Campaign Plan, and formulates significant systematic and logically designed products to unite the CSAs vision with the Army Program. All other Deputy Chief of Staff offices are peripherally responsible for generating requirements that lead to materiel solutions, but the ODCSPRO breathes life into these solutions. No where else on the Army Staff can materiel solutions be found that meet the CINCs requirements in design, development, testing, building, and fielding to the soldiers on the ground other than in ODCSPRO. The FISOS, DASCs, DISC4 liaisons, and Ols, working as a team, make these solutions a reality. Since the Force Development Directorate within ODCSPRO is the only staff element capable of providing the linkage between the CSA's vision, the Transformation Campaign Plan, and fielding materiel solutions, further realignment of the TDA is required to incorporate these vital members of the team into FD.

WORD COUNT: 6699 


\section{ENDNOTES}

${ }^{1}$ U. S. Army War College, Department of Command Leadership and Management, How The Army Runs, A Senior Leader Reference Handbook, (Carlisle Barracks, PA.: U. S.

Department of the Army, 2001), 1-1.

2 Ibid., 2-8.

3 lbid., 2-3.

${ }^{4}$ Dave Griffiths, "How to Reform the Pentagon's Wasteful Ways," Business Week, (27 May 1985): 58.

${ }^{5}$ Goldwater-Nichols Department of Defense Reorganization Act of 1986, Public Law 99-433 (100 Stat. 992-1000), $99^{\text {th }}$ Congress.

${ }^{6}$ Ibid.

${ }^{7}$ Ibid.

${ }^{8}$ Ibid.

${ }^{9}$ Department of the Army, Organization and Functions, Army Regulation 10-5 (Washington, D.C.: U.S. Department of the Army, 30 Nov 1992), 15.

${ }^{10}$ Congress, House, Committee on Armed Services, Bill Nichols Department of Defense Reorganization Act of 1986, Report of the House Committee on Armed Services Pursuant to H.R. 4370, (Report 99-700), $99^{\text {th }}$ Congress, 1986.

${ }^{11}$ Frank N. Schubert and Theresa L. Kraus, eds., "The Whirlwind War, Quicksilver Restructuring Initiatives," 1 August 2000; available from <http://wnw. army. mil/cmh$\mathrm{pg} / \mathrm{books} / \mathrm{wmw} / \mathrm{www} 2 . \mathrm{htm}>$; Internet; accessed 14 January 2002; 41.

12 Department of the Army, Materiel Requirements, Army Regulation 71-9 (Washington, D.C.: U.S. Department of the Army, 30 April 1997), 2.

${ }^{13}$ Sean D. Naylor, "Big Changes Ahead for Army HQ, More Defined Roles Planned For Staff, Secretariat; Management of Installations to be Reorganized," Army Times, (31 December 2001): 6 .

${ }^{14}$ How The Army Runs, 2-3.

${ }^{15} \mathrm{lbid}$, Paragraphs 4-11C and d.

${ }^{16}$ Department of the Army, Center for Army Analysis, Roles and Missions, December 2001, available from <http://www.caa.army.mil/default.html>, Internet accessed 12 December 2001.

${ }^{17}$ Department of the Army, Office of the Deputy Chief of Staff for Programs, ODCSPRO Implementation Plan, (Washington: U. S. Department of the Army, December 2001).

${ }^{18}$ Naylor, 6. 
${ }^{19}$ ODCSPRO Implementation Plan.

${ }^{20}$ Ibid.

${ }^{21}$ Department of the Army, Office of the Deputy Chief of Staff for Operations, Functional Responsibilities, Washington: U. S. Department of the Army, December 2001).

22 Ibid. 


\section{BIBLIOGRAPHY}

Goldwater-Nichols Department of Defense Reorganization Act of 1986. Public Law 99-433 (100 Stat. 992-1000), 99 ${ }^{\text {th }}$ Congress.

Griffiths, Dave. "How to Reform the Pentagon's Wasteful Ways." Business Week, 27 May 1985, 58.

Naylor, Sean D. "Big Changes Ahead for Army HQ, More Defined Roles Planned for Staff, Secretariat; Management of Installations to be Reorganized." Army Times, 31 December $2001,6$.

Schubert, Frank N., and Kraus, Theresa L., eds. "The Whirlwind War, Quicksilver Restructuring Initiatives." 1 August 2000. Available from: <http://www.army. mil/cmh$\mathrm{pg} / \mathrm{books} / \mathrm{mm} / \mathrm{mww} 2 . \mathrm{htm}>$. Internet. Accessed 14 January 2002. 41.

U. S. Army War College. Department of Command Leadership and Management. How The Army Runs, A Senior Leader Reference Handbook. Carlisle Barracks, PA.: U. S. Department of the Army, 2001.

U.S. Congress. House. Committee on Armed Services. Bill Nichols Department of Defense Reorganization Act of 1986, Report of the House Committee on Armed Services Pursuant to H.R. 4370 (Report 99-700). 99 ${ }^{\text {th }}$ Congress. 1986.

U.S. Congress. House. Committee on Armed Services. Reorganization Proposals for the Joint chiefs of Staff, Hearings Before the Investigations Subcommittee of the Committee on armed Services. $97^{\text {th }}$ Congress. 1982.

U.S. Congress. House. Committee on Armed Services. Reorganization Proposals for the Joint Chiefs of Staff, Hearings Before the Investigations Subcommittee of the Committee on Armed Services. $98^{\text {th }}$ Congress, 1983.

U.S. Congress. Senate. Committee on Government Operations. Administration of National Security: Selected Papers Prepared by the subcommittee on National Security Staffing and Operations Pursuant to S. Res. 332. $87^{\text {th }}$ Congress. 1962.

U. S. Department of the Army. Center for Army Analysis. "Roles and Missions." December 2001. Available from <http://wmw. caa.army.mil/default.html>. Internet. Accessed 12 December 2001.

U.S. Department of the Army. Materiel Requirements. Army Regulation 71-9. Washington, D.C.: U.S. Department of the Army, 30 April 1997.

U.S. Department of the Army. Office of the Deputy Chief of Staff for Operations. Functional Responsibilities. Briefing slides with commentary. Washington, D. C.: Department of the Army, December 2001.

U.S. Department of the Army. Office of the Deputy Chief of Staff for Programs. ODCSPRO Implementation Plan. Briefing slides. Washington, D. C.: U. S. Department of the Army, December 2001.

U.S. Department of the Army. Organization and Functions. Army Regulation 10-5. Washington, D.C.: U.S. Department of the Army, 30 November 1992. 